\title{
Highly Restricted Origin of Prefrontal Cortical Inputs to Striosomes in the Macaque Monkey
}

\author{
Frank Eblen ${ }^{1,2}$ and Ann M. Graybiel ${ }^{1}$ \\ 'Department of Brain and Cognitive Sciences, Massachusetts Institute of Technology, Cambridge, Massachusetts \\ 02139 and ${ }^{2}$ Neurologische Universitätsklinik Tübingen, 72076, Tübingen, Germany
}

The prefrontal cortex is made up of neocortical areas thought to mediate aspects of the temporal and spatial organization of behavior. One of the prime output targets of the prefrontal cortex is the striatum, which is thought to operate in series with the prefrontal cortex in some neural computations. We have analyzed this prefrontostriatal projection in cynomolgus monkeys by combining anterograde neuronal tract tracing methods with neurochemical markers for the striosome and matrix compartments of the striatum. Our results single out two parts of the frontal cortex as projecting densely to the striosome compartment of the striatum: the posterior orbitofrontal/ anterior insular cortex and the mediofrontal prelimbic/anterior cingulate cortex. These areas jointly innervated striosomes in the anterior and ventromedial striatum, mainly in the caudate nucleus. Striosomes in the dorsolateral striatum were never labeled. Thus, the anatomical subsystem defined by striosome affiliation includes three cortical and striatal regions that, in humans, have been implicated in obsessive-compulsive disorder. Nearly all of the remaining parts of the prefrontal cortex studied projected preferentially to the matrix compartment. Most of these prefrontal inputs were also patchy, and many of the patches (matrisomes) were selectively paired with nearby striosomes. The highly fractionated organization of prefrontal inputs to striosomes and matrisomes could form a template for computational networks in the striatum that redistribute prefrontal corticostriatal inputs to serve in context-dependent behavioral planning.

[Key words: frontal lobe, caudate nucleus, orbitofrontal cortex, anterior cingulate cortex, obsessive-compulsive disorder, basal ganglia]

Clinical, neurobehavioral, and imaging studies have established broad functional subdivisions within the prefrontal cortex. Parts of the lateral convexity cortex are selectively activated during tasks engaging spatial working memory and behavioral planning (Frith et al., 1991; Sawaguchi and Goldman-Rakic, 1991; Fu-

\footnotetext{
Received Jan. 20 1995; revised Apr. 14, 1995; accepted Apr. 24, 1995.

This study was supported by NIH Javits Neuroscience Investigator Award R01NS25529, the Human Frontier Science Project, and Deutsche Forschungsgemeinschaft (Eb 127/1-1 to FE.). We thank Drs. E. J. Tehovnik, K.-M. Lee and P. H. Schiller for contributing monkey $3 \mathrm{~A}$; Mr. H. F. Hall, who is responsible for the photography; Mr. G. C. Holm for computer assistance; and Ms. D. Major and Ms. A. M. Rosales for help with the histology.

Correspondence should be addressed to Dr. Ann M. Graybiel, Department of Brain and Cognitive Sciences, Massachusetts Institute of Technology, E25618, 45 Carleton Street, Cambridge, MA 02139.

Copyright $\odot 1995$ Society for Neuroscience $0270-6474 / 95 / 155999-15 \$ 05.00 / 0$
}

nahashi et al., 1993; Petrides et al., 1993; for review, see Fuster, 1989). By contrast, medial prefrontal/anterior cingulate cortex and orbitofrontal cortex can be selectively activated in paradigms evoking emotional responsivity, response selection or suppression, and attention shifts (Rosenkilde et al., 1981; Ya mamoto et al., 1984; MacLean and Newman, 1988; Posner et al., 1988; Pardo et al., 1990, 1991, 1993; George et al., 1993; Paus et al., 1993). Regionally selective metabolic dysfunctions of the prefrontal cortex have also been found in major psychiatric disorders. In schizophrenic patients, tasks engaging the dorsolateral prefrontal cortex do not lead to increased activation of this area, as they do in normal subjects (Berman and Weinberger, 1990; Park and Holzman, 1992). Abnormalities in metabolic activity in the orbitofrontal cortex, medial prefrontal cortex, or both, have been found in major depression (Drevets et al., 1992), depression associated with Parkinson's and Huntington's diseases (Mayberg et al., 1900, 1992), obsessive-compulsive disorder (OCD; Baxter et al., 1988, 1992; Swedo et al., 1989, 1992; Benkelfat et al., 1990; Sawle et al., 1991; Rubin et al., 1992), Gilles de la Tourette syndrome (Baxter et al., 1990), and schizophrenia (Andreason et al., 1992).

Imaging studies of the basal ganglia have raised the possibility that in such neuropsychiatric illnesses, and also in the course of normal behavior, the prefrontal cortex operates in conjunction with the caudate nucleus (Baxter et al., 1988, 1992; Swedo et al., 1989; Drevets et al., 1992; Cummings, 1993; Rauch et al., 1994). This new evidence supports the concept developed from earlier anatomical and lesion studies that different areas of the prefrontal cortex interact with different parts of the caudate nucleus to form high-level functional subsystems within the forebrain (Teuber and Proctor, 1964; Iversen and Mishkin, 1970; Divac, 1972; Rosvold 1972; Iversen, 1979).

How are these proposed functional subsystems organized? The known connectivity between the prefrontal cortex and the caudate nucleus in primate already indicates that they have three interesting characteristics. First, the direct connections are one way, from the frontal cortex to the caudate nucleus. The caudate nucleus (and, more generally, the striatum) must project through several synaptic stations before its information is sent to the cortex (Graybiel, 1990; Parent, 1990). Second, the connections from the prefrontal cortex to the caudate nucleus, although broadly topographic, are "distributed" in the sense that any one small part of the cortex projects to a considerable extent of the caudate nucleus (Künzle, 1975; Goldman and Nauta, 1977; Yeterian and van Hoesen, 1978; Selemon and Goldman-Rakic, 1985). Finally, the prefrontal inputs to the caudate nucleus are organized in patchy patterns (Kün- 
Table 1. Summary of cases

\begin{tabular}{|c|c|c|c|c|c|c|c|}
\hline \multirow[b]{2}{*}{ Case } & \multirow[b]{2}{*}{ Cortical site } & \multirow[b]{2}{*}{ Area } & \multirow[b]{2}{*}{ Tracer } & \multirow[b]{2}{*}{ Amount } & \multicolumn{3}{|c|}{$\begin{array}{l}\text { Predominant } \\
\text { compartment }\end{array}$} \\
\hline & & & & & Strio & Matrix & Mixed \\
\hline $1 \mathrm{~A}$ & Frontal pole & 10 & met & $210 \mathrm{nl}$ & & & + \\
\hline $1 \mathrm{~B}$ & Principal/arcuate & 46 & WGA-HRP & $180 \mathrm{nl}$ & & + & \\
\hline $2 \mathrm{~A}$ & Posterior orbitofrontal & $13 / \mathrm{Ia}$ & met & $150 \mathrm{nl}$ & + & & \\
\hline $3 \mathrm{~A}^{a}$ & Principal sulcus & $8 / 46$ & met & $200 \mathrm{nl}$ & & + & \\
\hline $5 \mathrm{~A}$ & Lateral orbitofrontal & 11 & met & $370 \mathrm{nl}$ & & † & \\
\hline $6 \mathrm{~A}$ & Posterior orbitofrontal & $13 / \mathrm{Ia}$ & met & $140 \mathrm{nl}$ & + & & \\
\hline $6 \mathrm{~B}$ & Orbitofrontal & $12 / 13$ & WGA-HRP & $280 \mathrm{nl}$ & & & + \\
\hline $7 \mathrm{~A}$ & Posterior orbitofrontal & 13 & met & $\dagger$ & + & & \\
\hline $7 \mathrm{~B}$ & Orbitofrontal & 13 & WGA-HRP & $\dagger$ & & & + \\
\hline $8 \mathrm{~A}$ & Lateral orbitofrontal & 12 & met & $120 \mathrm{nl}$ & & + & \\
\hline $9 B$ & Medial prefrontal & 14 & WGA-HRP & $180 \mathrm{nl}$ & & + & \\
\hline $12 \mathrm{~A}$ & Anterior cingulate & $24 / 32$ & met & $180 \mathrm{nl}$ & + & & \\
\hline $12 \mathrm{~B}$ & Prelimbic/ant cingulate & $10 / 32$ & WGA-HRP & $200 \mathrm{nl}$ & & + & \\
\hline $13 \mathrm{~A}$ & Dorsolateral convexity & $9 / 46$ & met & $300 \mathrm{nl}$ & & + & \\
\hline $13 \mathrm{~B}$ & Inferior convexity & $12 / 46$ & WGA-HRP & $260 \mathrm{nl}$ & & + & \\
\hline $14 \mathrm{~A}$ & Prelimbic/ant. cingulate & 32 & met & $160 \mathrm{nl}$ & + & & \\
\hline $14 \mathrm{~B}$ & Prelimbic/ant. cingulate & 32 & WGA-HRP & $120 \mathrm{nl}$ & & + & \\
\hline $15 \mathrm{~A}$ & Gyrus rectus & $14 / 25$ & met & $100 \mathrm{nl}$ & & + & \\
\hline $16 \mathrm{~B}$ & Gyrus rectus & 14 & WGA-HRP & $160 \mathrm{nl}$ & & + & \\
\hline
\end{tabular}

See text and figures for further description of the cortical areas injected. met, L-[ ${ }^{35}$ S]-methionine; WGA-HRP, wheat germ agglutinin-conjugated horseradish peroxidase.

"Macaca mulatta.

$\uparrow$ Values uncertain.

zle, 1975; Goldman and Nauta, 1977; Ragsdale and Graybiel, 1981). These three characteristics have led to the notion that there are multiple prefrontal and premotor circuits in the basal ganglia (Graybiel, 1984; Alexander et al., 1986; Hoover and Strick, 1993), and to the idea that the modularity of input connections may be related to the intrinsic neurochemical compartments of the caudate nucleus, striosomes and matrix (Graybiel and Ragsdale, 1978, Graybiel et al., 1981), or to compartments within the matrix (Parthasarathy et al., 1992; Flaherty and Graybiel, 1994). In the experiments reported here and briefly in Eblen and Graybiel (1992, 1993), we directly tested these ideas by analyzing the connections of different sites in the prefrontal cortex with the striosomes and matrix of the caudate nucleus.

\section{Materials and Methods}

The distinguishable anterograde tracer substances, $\mathrm{L}^{-35} \mathrm{~S}$-methionine (DuPont New England Nuclear, Boston; $200 \mu \mathrm{Ci} / \mu \mathrm{l}$ in sterile saline) and a wheatgerm agglutinin-horseradish peroxidase conjugate (WGAHRP, Sigma, St. Louis, MO; $15 \%$ in sterile saline), were placed in orbital, medial, or lateral sites in the left prefrontal cortex of 10 adult female and 2 male cynomolgus monkeys (Macaca fascicularis). One lateral injection was made in an adult male rhesus monkey (Macaca mulatta) that had been used previously in chronic microelectrode recording studies (Tehovnik and Lee, 1990). Successful injections are listed in Table 1.

Injection protocols. Anesthesia was induced with ketamine hydrochloride i.m. and was maintained with a mixture of ketamine hydrochloride and xylazine i.m. Fluids (lactated Ringer's solution) were delivered during surgery by an intravenous catheter, and anesthetic levels were determined by monitoring heart rate, respiratory rate, and reflexes. Surgeries were performed under sterile conditions with the animal's head in a Kopf stereotaxic headholder. Bone and dural flaps were turned over the intended injection sites, tracers were injected with hand-held $1 \mu \mathrm{l}$ Hamilton syringes, and the surgical opening was closed in layers.
A total of $0.08-0.18 \mu \mathrm{l}$ of tracer was delivered in $0.01-0.02 \mu \mathrm{l}$ aliquots over a period of several minutes at two or more closely spaced locations for each injection site (see Table 1).

Tissue preparation and histology. Brains were perfused after $48-72$ hour survival periods by transcardial perfusion with the animals deeply anesthetized with ketamine hydrochloride $(10 \mathrm{mg} / \mathrm{kg}$ i.m.) and Nembutal (10-15 $\mathrm{mg} / \mathrm{kg}$ i.p.). Perfusion solutions given were, in sequence, heparinized saline, $4 \%$ paraformaldehyde in $0.1 \mathrm{M}$ phosphate-buffered saline (PBS) containing 5\% sucrose, and PBS containing 5\% sucrose. The brains were cut coronally at $40 \mu \mathrm{m}$ on a freezing microtome, and the sections were stained or processed for autoradiography as described earlier (Flaherty and Graybiel, 1991; Parthasarathy et al., 1992). For autoradiography, every sixth section was slide mounted, dipped in NTB-2 liquid emulsion (Kodak), and exposed for $10 \mathrm{~d}$ to 6 weeks, developed in Kodak D-19 at $15^{\circ} \mathrm{C}$, and counterstained with cresylecht violet. WGA-HRP staining was carried out on other series of sections by the tetramethylbenzidine (TMB) protocol of Mesulam (1978) with slight modifications (Parthasarathy et al., 1992). Sections serially adjoining those prepared to demonstrate the transported label were stained for acetylthiocholinesterase ( $\mathrm{AChE}$; Geneser-Jensen and Blackstad, 1971; Graybiel and Ragsdale, 1978) or for Met-enkephalin-like immunoreactivity (Parthasarathy et al., 1992). Striosomes were identified as circumscript zones with low Acht activity, differentially low enkephalin immunostaining of cell bodies (Graybiel and Chesselet, 1984), or their distinctive neuropil enkephalin immunostaining.

Data analysis. Sections were studied under bright-field and dark-field illumination and, for WGA-HRP reaction product, with cross-polarized dark-field illumination (Illing and Wässle, 1979). The injection sites were reconstructed in serial sections with sulci and gyri visible on the brain photographs serving as landmarks. Borders of the effective injection sites were estimated by eye, as described by Parthasarathy et al. (1992), following the maps of Walker (1940), Mesulam and Mufson (1982), Morecraft et al. (1992), Ray and Price (1993), and Carmichael and Price (1994). Distributions of transported label in the striatum were charted with the aid of a dissecting microscope coupled to a drawing tube. Scoring of the labeled corticostriatal fiber distributions as lying in striosomes or in matrix or in both was done by comparing the experimentally labeled distributions with the patterns of staining visible in 


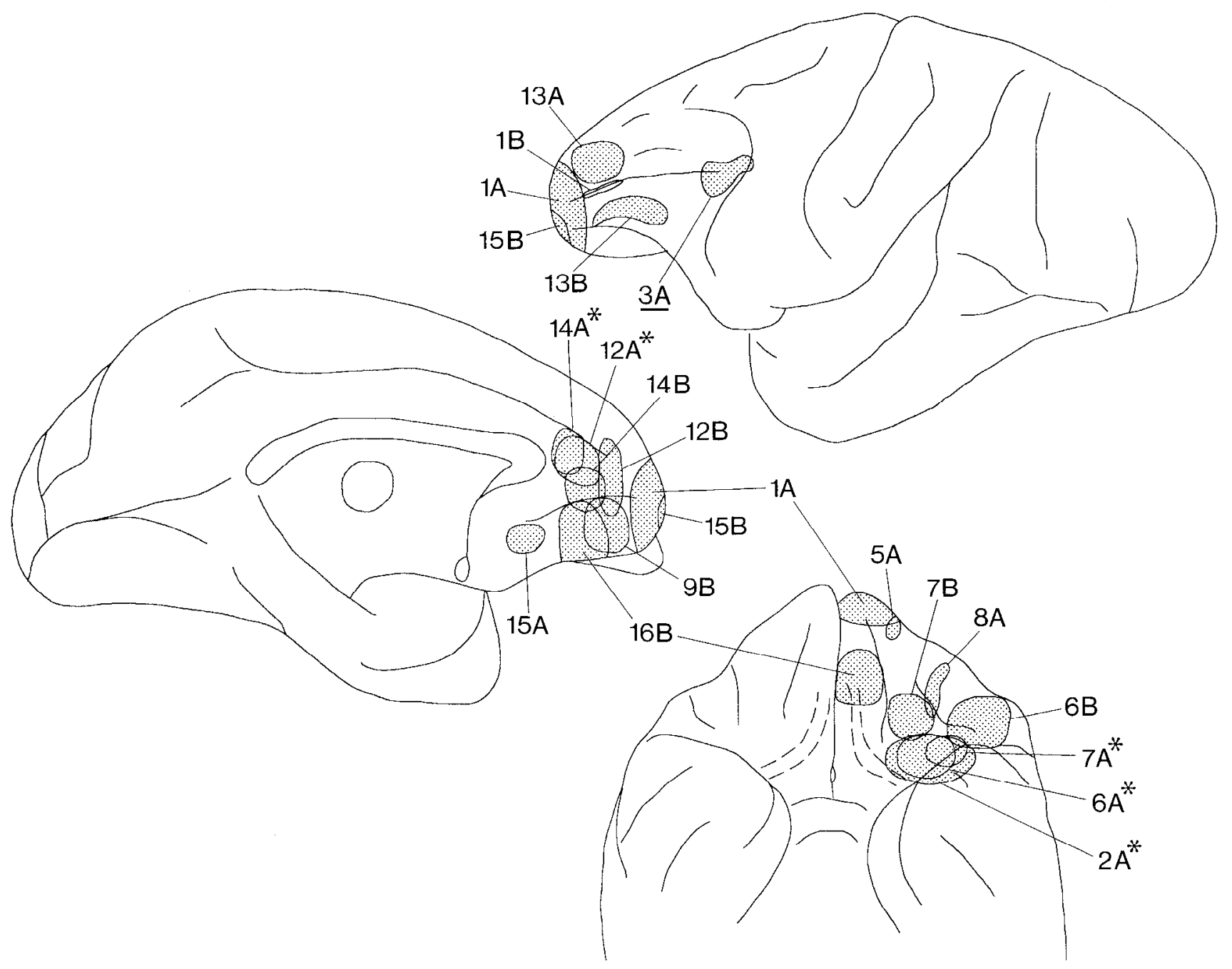

Figure 1. The locations of anterograde tracer injection sites shown in semischematic lateral, medial, and ventral views of the left hemisphere of a cynomolgus macaque monkey brain. Case numbers ending with $A$ indicate sites at which injections of $\mathrm{L}^{-35} \mathrm{~S}$-methionine were made. Case numbers ending with $B$ indicate cases with WGA-HRP injection sites. Case numbers with * indicate cases with strong projections to striosomes. Case 3 A was a Macaca mulatta.

adjacent sections processed either for AChE activity or for enkephalinlike immunoreactivity. Striosomes detected by the two markers were coincident in regions in which both stains were successful, but there were variations from monkey to monkey in the quality of the two stains, and there were regional variations in the staining patterns as well as heterogeneous staining of the matrix, especially in the enkephalin-immunostained sections. In the ventral parts of the caudoputamen, both marker distributions were complex and, when possible, both were studied to evaluate the compartmentalization of tracer labeling (Graybiel and Chesselet, 1984; Martin et al., 1991). All identifications of striosomes and matrix reported were made with these technical limitations and qualifications.

\section{Results}

General plan of the prefrontostriatal projection in the macaque

Figure 1 illustrates the locations of the three groups of injection sites made: six injections in the medial, lateral, and posterior periallocortical orbital cortex; seven injections in the medial prefrontal cortex, except in its most dorsal part; two injections in the frontal pole; and four injections in the lateral convexity cortex that were, respectively, dorsal, ventral, posterior to the principal sulcus, and within it. The deposits extended through all cortical layers but did not always infiltrate them equally. Thus, most of the prefrontal cortex was included in the present study, exceptions being the dorsal part of the medial prefrontal cortex including area 9 and the ventral cortex stretching between the orbital and medial prefrontal areas.

Regardless of the placement of the cortical injection sites, the labeled prefrontostriatal projections extended through a considerable volume of the striatum, always including the head of the caudate nucleus. Viewed in cross-section, they were distributed within discontinuous, diagonally oriented fields. The most intense and most patchy labeling was in the head of the ipsilateral caudate nucleus. The putamen also was labeled in all cases, usually less strongly (Fig. 2). All injected cortical sites also projected contralaterally, but the contralateral striatal labeling was weaker than that on the ipsilateral side and usually was visible only at anterior-posterior levels at which the strongest ipsilateral labeling occurred. Our analysis was restricted to the ipsilateral side.

The prefrontal projections to the striatum were invariably most broadly distributed in the anterior part of the striatum, and farther caudally became progressively restricted to fields stretching from the medial and dorsomedial caudate nucleus to the 


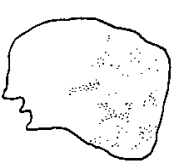

$12 \mathrm{~A}$

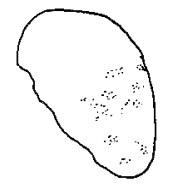

$6 \mathrm{~A}$

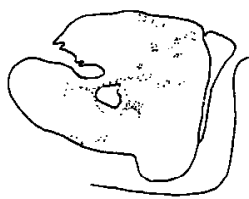

$1 \mathrm{~B}$
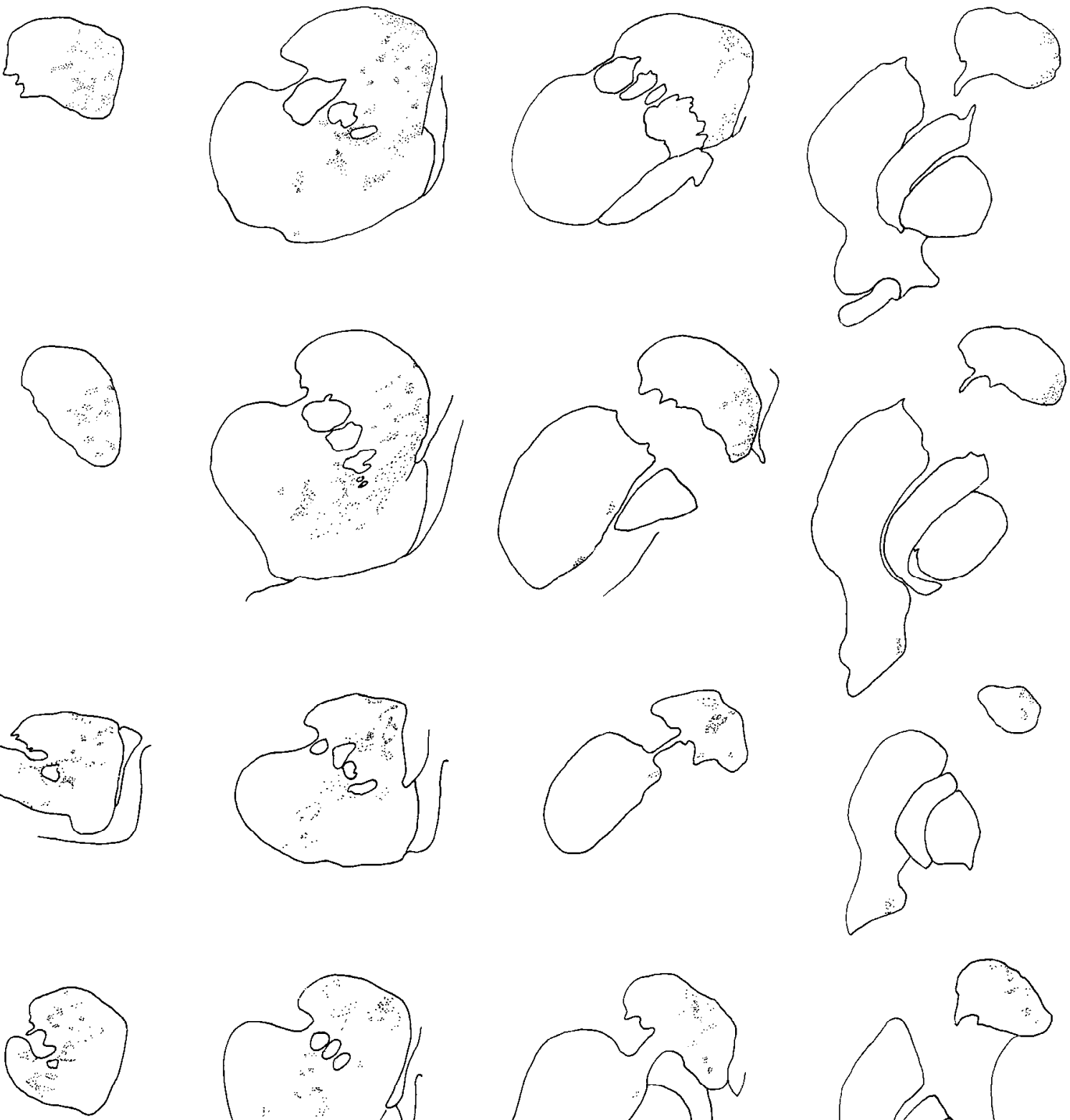

$5 \mathrm{~A}$
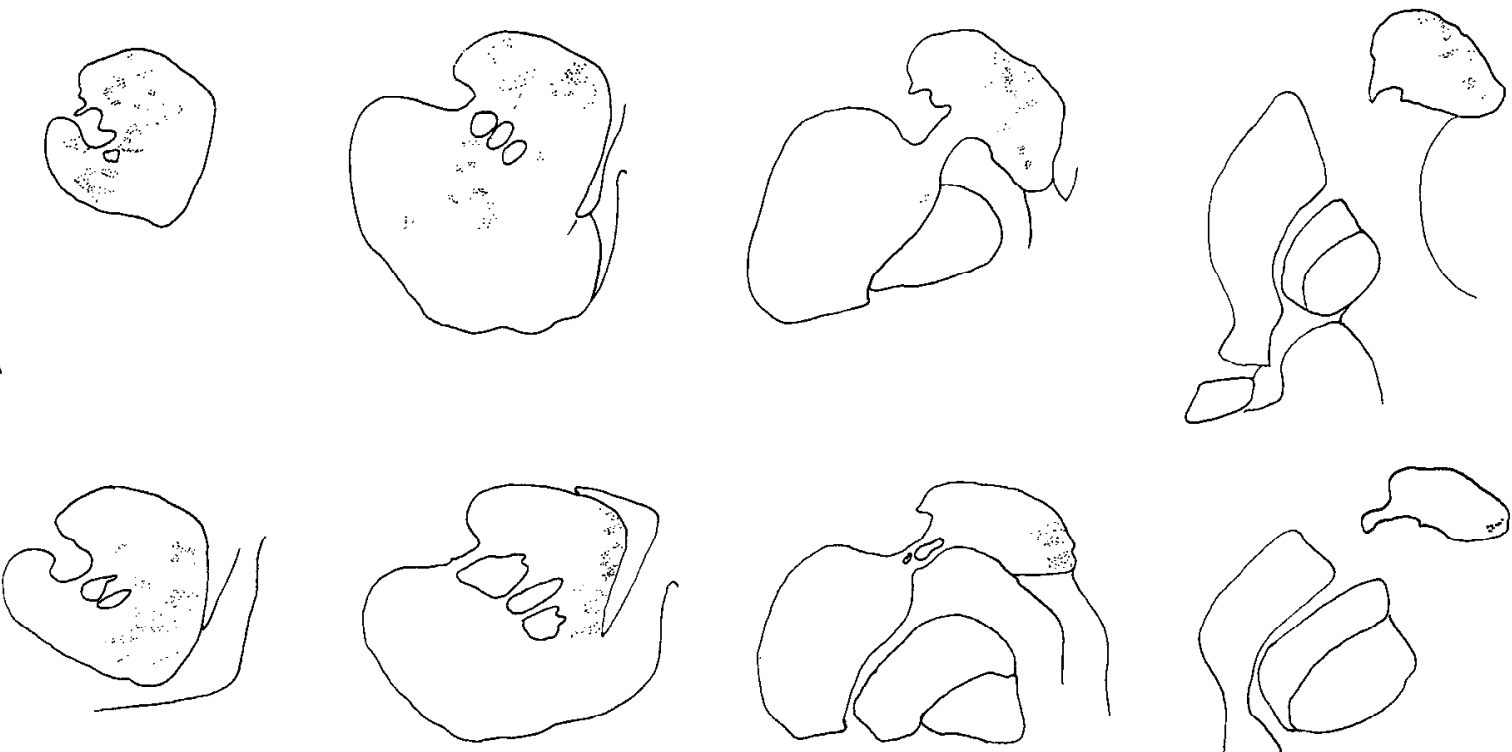

15B

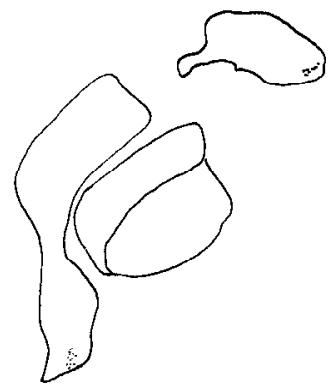

Figure 2. The topography of the prefrontostriatal projection. Each series of semischematic drawings shows four coronal sections through the striatum illustrating, from left to right, the level of the head of the caudate nucleus, the level of the nucleus accumbens, the level of the anterior commissure, and the level of the globus pallidus. Case 12A: injection of medial prefrontal cortex; case 6A, injection of posterior orbital cortex; case $1 B$, injection of principal sulcal cortex; case $5 A$, injection of lateral orbital cortex; case $15 B$, injection of frontal pole. See also Figure 1. 
A
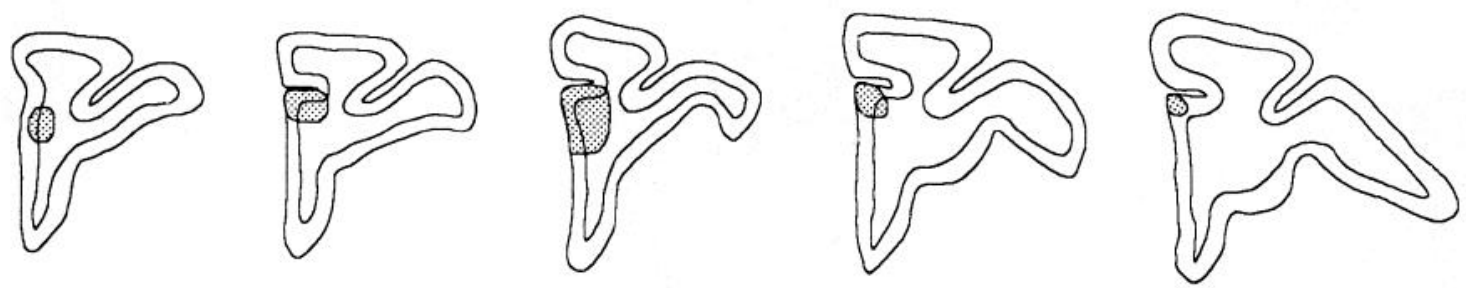

$12 \mathrm{~A}$
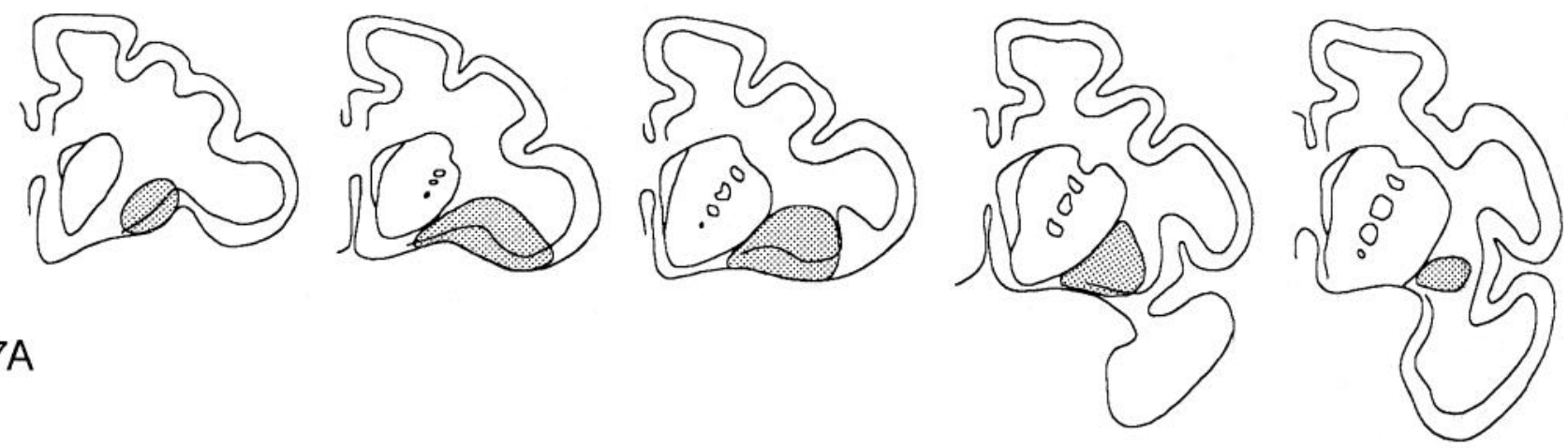

$7 \mathrm{~A}$
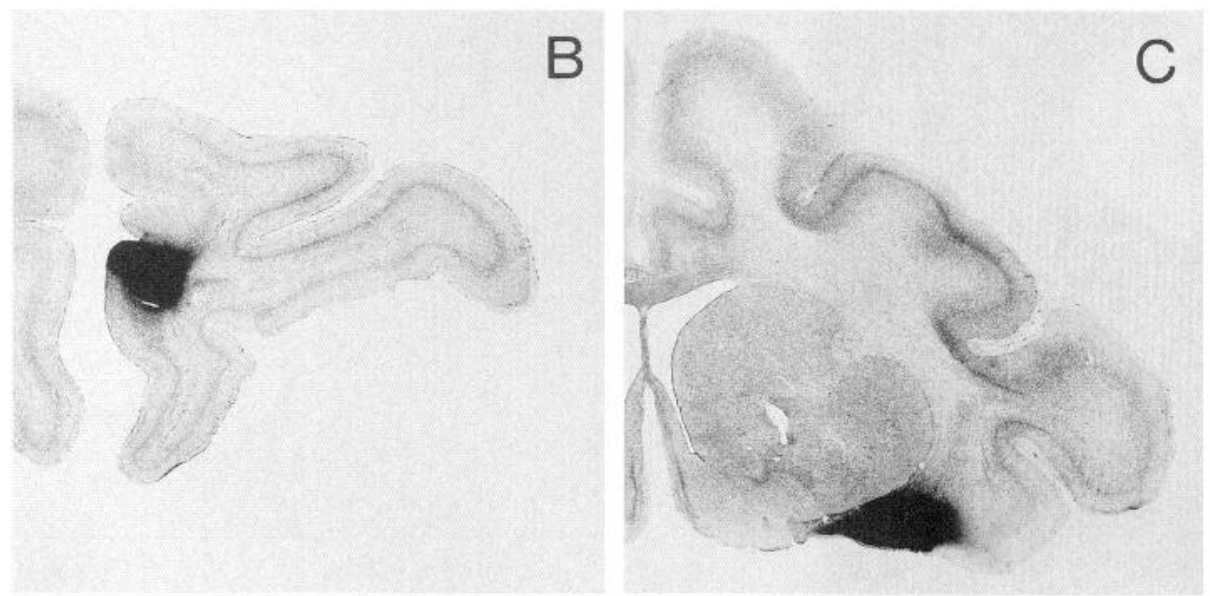

Figure 3. Examples of prefrontal cortical injection sites that led to selective corticostriatal labeling of striosomes. A, Schematic drawings of coronal sections display the anteroposterior extents of the injection sites of medial prefrontal/anterior cingulate case $12 \mathrm{~A}$ and posterior orbitofrontal/anterior insula case 7A. Photographs of the injection sites are shown in $B$ for case $12 \mathrm{~A}$ and in $C$ for case $7 \mathrm{~A}$.

medial and ventromedial putamen. It was also in the anterior sections that compartmentalization of the labeled projections was most pronounced and consistent. In more caudal sections, the labeling pattern changed, becoming more diffuse and shifting toward the ventral margins of the body and tail of the caudate nucleus and the posterior putamen.

A general topography of the prefrontostriatal projection was apparent in that inputs from the lateral prefrontal regions (such as cortex associated with the principal sulcus and the lateral orbitofrontal cortex) reached farther laterally and dorsally in the caudate nucleus than did more inputs from caudal and medial parts of the prefrontal cortex (Fig. 2). However, it was striking that the fiber systems traced from posterior orbitofrontal cortex and from the medial prelimbic/anterior cingulate cortex had overlapping distributions (Fig. 2). The frontal pole projected predominantly to a medial sector of the caudate nucleus lying along the ventricular wall (Fig. 2).
Selective targeting of striatal compartments by fibers from the macaque prefrontal cortex

The compartmental analysis yielded four clear-cut results. First, nearly all of the sites in the prefrontal cortex injected, whether orbital, medial, or lateral, preferentially innervated the matrix compartment of the caudate nucleus. The only exceptions were sites in the posterior orbital and posterior medial prefrontal cortex, which preferentially innervated sets of striosomes in the caudate nucleus (Figs. 1, 3; Table 1). Second, even with injections at these striosome-projecting cortical sites, many striosomes in the lateral and caudal parts of the caudate nucleus were never detectably labeled, and there was little labeling of striosomes in the putamen except ventromedially. Thus, the prefrontal corticostriatal system does not innervate all striosomes in the macaque striatum. Third, even in cases with robust and selective labeling of striosomes, there were 

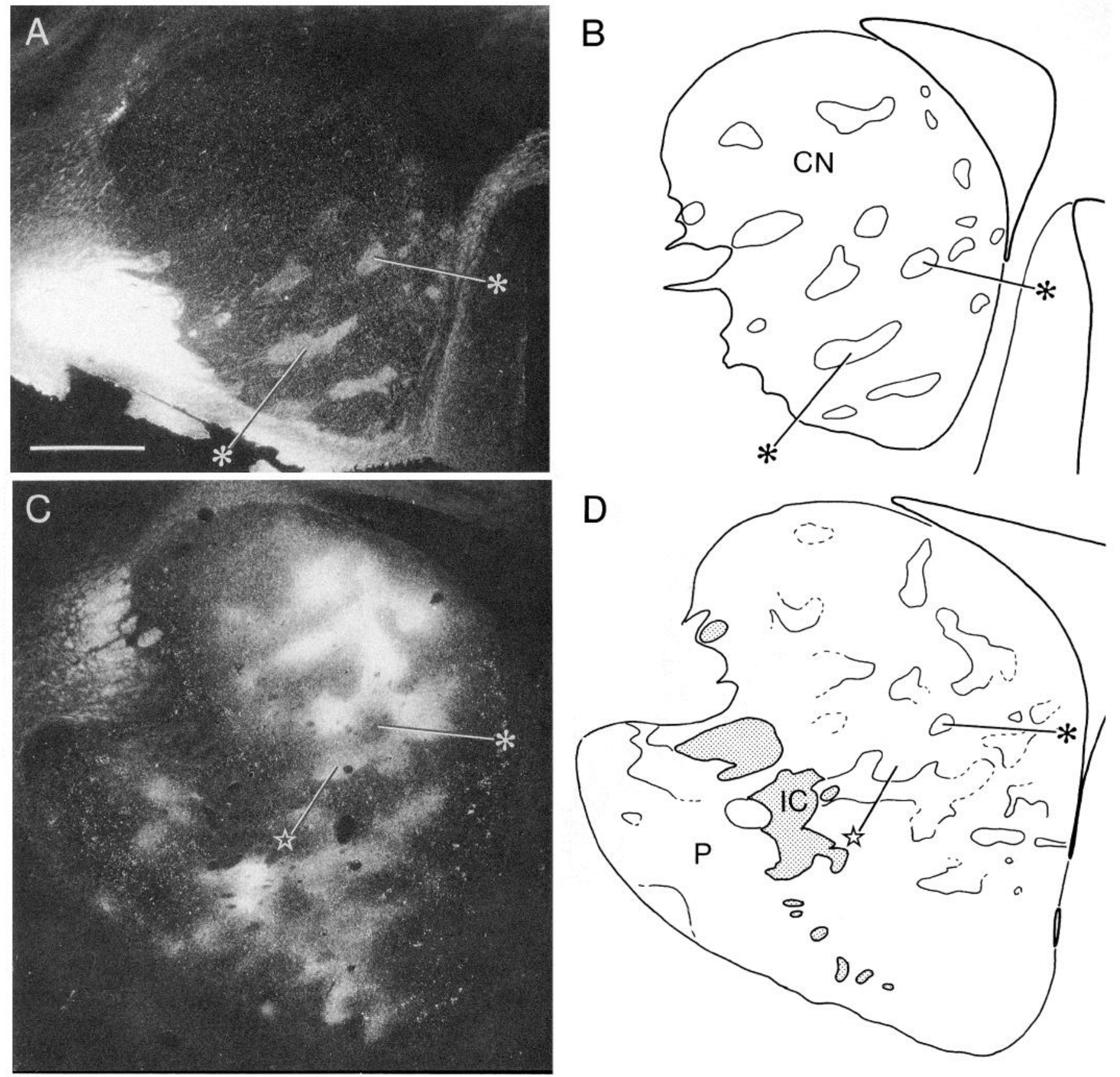

Figure 4. Different regions of the macaque prefrontal cortex target striosomes and matrix. $A$ and $B$, Serial sections illustrating predominant projection to striosomes in case 7A labeled by an injection of ${ }^{35} \mathrm{~S}$-methionine into the posterior orbital cortex (see Fig. 3 for injection site). $A$ shows dark-field micrograph of a coronal section through the rostral part of the caudate nucleus. Labeling, which appears white, is mainly in discrete patchy foci. $B$ shows drawing of a section adjacent to that illustrated in $A$ and displays striosomes as detected by AChE histochemistry ( fine outlines, examples at asterisks). Corresponding locations in $A$ are similarly marked. Note that the labeled input patches in $A$ match precisely the striosomes shown in $B$. $C$ and $D$, A pair of serial sections through the left anterior caudate nucleus of case $13 \mathrm{~A}$, in which the injection site was in the dorsolateral prefrontal cortex (see Fig. 1). The autoradiogram in $C$ illustrates the distribution of labeled corticostriatal fibers. $D$ shows drawing of the adjoining section, stained for enkephalin-like immunoreactivity to indicate striosomes (fine outlines, example at asterisk). Note that this prefrontal projection largely avoids striosomes: when a patch of label is visible, it is in the matrix (example at star). Stipple indicates internal capsule (IC). $C N$ - caudate nucleus, $P$-putamen. Scale bar in $A$ indicates $2 \mathrm{~mm}$.

variable amounts of accompanying labeling of the ventromedial matrix. These innervation patterns took the form of obliquely oriented fields of dorsal innervation with preferential striosomal labeling and a ventromedial region in which striosomes (insofar as they could be identified with confidence) were not selectively targeted. Thus, striosome-selective fields of prefrontal innervation were accompanied by a generally more ventromedial labeling in the matrix. Finally, the much more broadly derived prefrontal inputs to the matrix compartment of the striatum were themselves heterogeneously distributed, and in some cases, such compartments were at least partially coincident with zones of enhanced enkephalin-like im- 

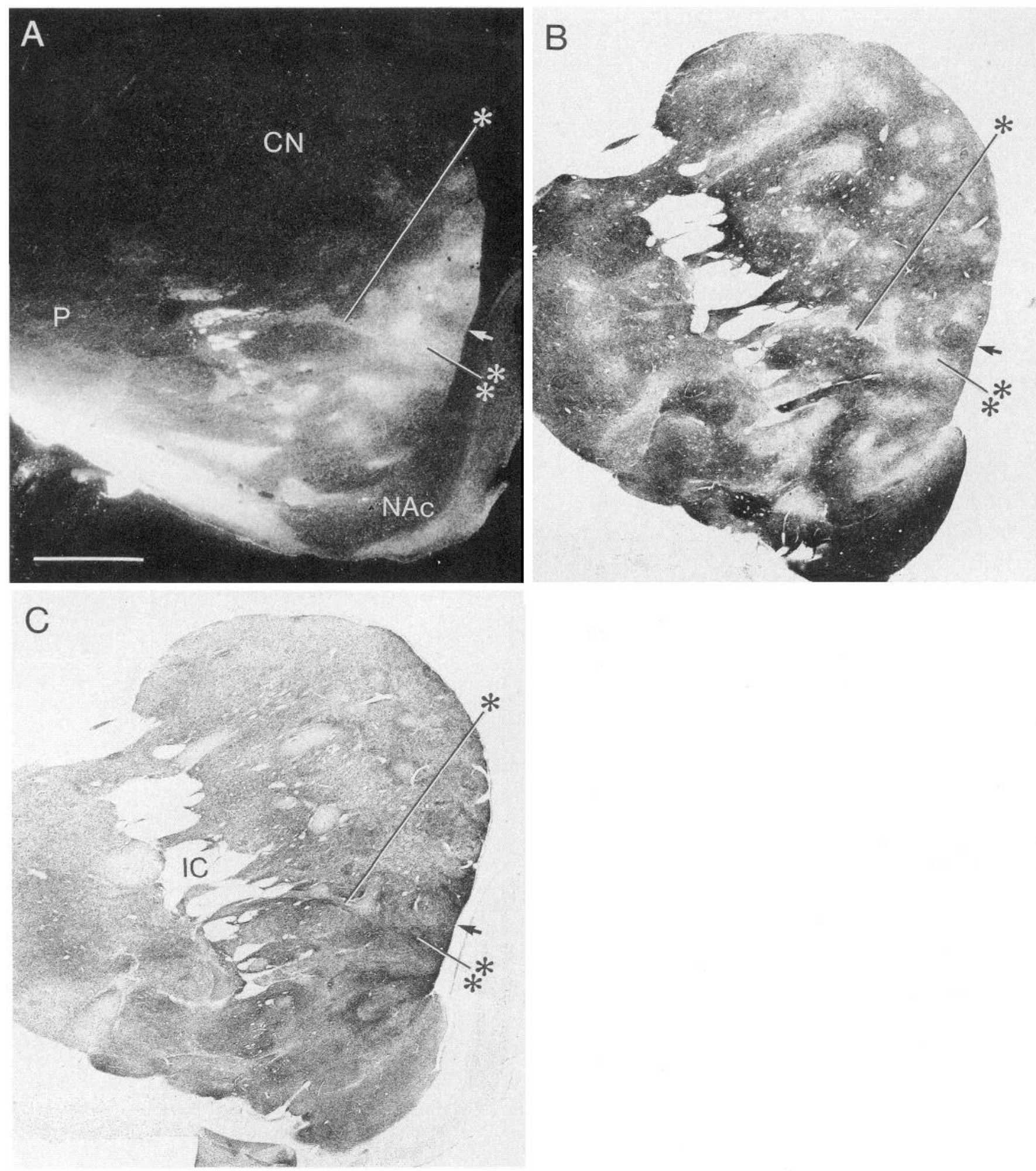

Figure 5. Posterior orbital cortex has a striatal projection that is only partly selective for striosomes. A, Distribution of autoradiographic labeling in the caudate nucleus of case 7A, illustrated at a level slightly more caudal level than that shown in Figure $4 A . B$ and $C$, Photomicrographs of sections adjacent to the one shown in $A$ stained, respectively, for $\mathrm{AChE}$ activity $(B)$ and for enkephalin-like immunoreactivity $(C)$. Note that dorsally and laterally (and anteriorly, see Fig. $4 A$ ), the label fills AChE-poor striosomes (see asterisks). Ventromedially, the label is also heterogeneously distributed but occurs both in striosomes and in matrix. Single and double asterisks in B indicate two AchE-poor striosomes that are innervated by labeled fibers. The more dorsal one (single asterisk) is enkephalin-poor, but the lower more ventral striosome has enkephalin-rich neuropil (double asterisks); cf. Graybiel et al. (1981); Martin et al. (1991). The dorsal striosome is illustrated at higher magnification in Figure 6. Note that discrete parts of the matrix are avoided by the input label (example at arrow). The nucleus accumbens $(N A c)$ is devoid of label. $C N-$ caudate nucleus, $P-$ putamen. Scale bar in $A$ indicates $2 \mathrm{~mm}$. 

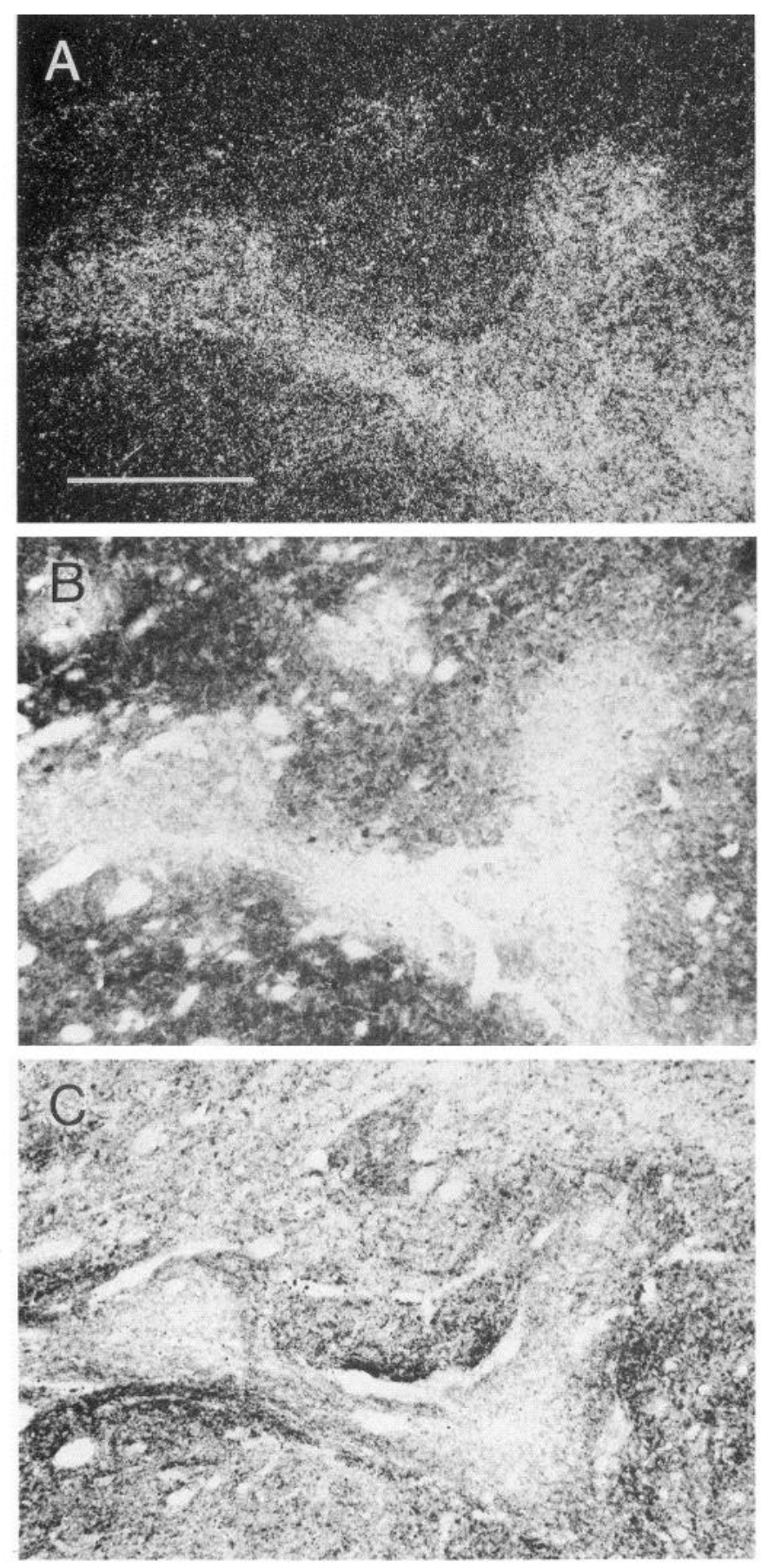

Figure 6. Posterior orbitofrontal input to histochemically identified striosome. Photomicrographs of the striosome shown by single asterisk in Figure 5, illustrating enhanced ${ }^{35} \mathrm{~S}$-methionine labeling of the striosome $(A)$, identified both by its AChE-poor neuropil $(B)$ and by its relatively low enkephalin-like immunoreactivity $(C)$. Scale bar indicates $0.5 \mathrm{~mm}$. munoreactivity. Thus, both striosome-directed and matrix-directed prefrontostriatal projections are compartmentalized. These points are documented below, together with the topographies of the prefrontal input systems identified.

\section{Restricted origins of prefrontal projections to striosomes}

Selective innervation of striosomes was found for only 5 of the 20 cortical injections made. Three of the injections sites involved the posterior orbital cortex, and the other two were centered in the medial prelimbic cortex at its border with the anterior cingulate cortex.

The injection sites in the posterior orbitofrontal cortex involved posterior area 13 as well as the anterior insula and parts of the underlying claustrum (Fig. 3). The patterns of corticostriatal projection in these cases were similar and are illustrated by case 7A in Figures 4-6. Strongly labeled clusters of orbitofrontal fibers appeared ventrally in the head of the caudate nucleus and, farther caudally, in a diagonally oriented zone that extended from the medial border of the caudate nucleus to the ventrolateral putamen. The labeled input clusters corresponded to striosomes identified in adjacent sections.

In contrast to this pronounced orbitofrontal innervation of striosomes, labeling in the matrix surrounding the innervated striosomes was at or near baseline levels of intensity rostrally. However, at slightly more caudal levels, as the field of predominant striosomal labeling became weaker (Fig. 5), strong label began to appear in the medial part of the caudate nucleus, and this was mainly in the matrix compartment. Thus, rostrally and dorsally within the distribution field of the orbitofrontal fibers, striosomes were selectively labeled, but medially and ventrally the striosomes were not. The fields of differential striosome and matrix labeling were connected with one another at the level shown in Figure 5 by fingers of labeling matching striosomes that stretched laterally toward the zone of weaker striosome labeling. The periventricular band of matrix labeling was itself heterogeneous. There were zones of weaker labeling its ventral part, and these zones, like the associated band of labeling, were within the matrix compartment. At caudal levels, the weak, diffuse labeling still visible was confined to the ventral tip of the body and tail of the caudate nucleus, and could not be assigned to either striosome or matrix compartments. As shown in Figure 5 , the nucleus accumbens was not detectably labeled.

The characteristic pattern of labeling found in the cases of medial prelimbic injection is illustrated in Figure 7. The injection sites in these cases were situated in the cortex immediately anteriorly to the rostral tip of the corpus callosum. They appeared to involve area 32 and caudally area 24 . Labeling at rostral levels of the striatum appeared in crisp patches identified as striosomes (data not shown). At more caudal levels, a clear change in the labeling pattern occurred, so that there was a marked distinction between the dorsal, central, and ventral parts of the projection field. Dorsally, the labeling was weak but co-

Figure 7. Dorsal and ventral caudoputamen are differently innervated by a single prefrontal cortical region in relation to enkephalin-immunostained compartments. A, Dark-field micrograph demonstrating the patchy autoradiographic labeling in the caudate nucleus following injection of the posterior medial prefrontal cortex (case 14A). $B$, Section adjacent to $B$, stained for enkephalin-like immunoreactivity. $C$, Overlay charting of sections shown in $A$ and $B$, with striosomes shown by fine outlines and densely labeled projections shown by dots. The internal capsule (IC) is shown in stipple, with jet black to indicate densely labeled capsular fiber bundles. In the most dorsal part of the projection field, striosomes appear to be faintly labeled (examples at asterisks). Most of the labeling in the medial caudoputamen is in the matrix. In the ventromedial striatum, there are patches of labeled input fibers. Some of these correspond to enkephalin-rich zones next to enkephalin-poor striosomes (examples at arrows). $C N-$ caudate nucleus, $P$-putamen. Scale bar in $A$ indicates $2 \mathrm{~mm}$. 


incided with striosomes (Fig. $7 A$ and $7 B$ ). Centrally, the strongest label was found outside striosomes, and the labeled zones actually interdigitated with striosomes detected by either AChE activity or enkephalin-like immunoreactivity (Fig. 7C). Finally, in the ventromedial sector, no association with enkephalin-poor zones was obvious, but some of the labeling was found to coincide with or to occupy parts of zones of strong enkephalinlike immunoreactivity (Fig. 7C). Thus, for the medial prelimbic/ anterior cingulate cortex injected, we found evidence for a general projection pattern similar to the one observed in the posterior orbitofrontal cases.

\section{Prefrontal projection systerns innervating the matrix}

Even in the posterior orbitofrontal and medial prefrontal/anterior cingulate cases, there was at least some labeling of fibers innervating the striatal matrix medially and ventrally. However, in all other cases except one, the matrix was the principal target of the prefrontal input when the injection sites did not overlap the orbitofrontal or posterior mediofrontal sites.

In monkeys in which the dorsolateral prefrontal cortex or cortex in and near the principal sulcus was injected, there was dense and apparently nearly uniform labeling of the matrix within the striatal projection fields (Fig. 2). There were pockets of very low, nearbackground levels of labeling within these fields, and every such zone that we could score corresponded to a striosome. This projection pattern is shown in Figure 2 for case $1 \mathrm{~B}$, in which a large tracer deposit was placed in the dorsal and ventral banks of the principal sulcus. A similar projection pattern was seen in case $13 \mathrm{~A}$, in which a large injection of tracer was made in the dorsolateral prefrontal cortex (Fig. $4 B$ ). It was notable that within the main projection fields labeled in these cases, the labeled innervation appeared nearly to fill the matrix; the borders of the field were themselves irregular with some outlying patches of label, but the main field was strongly labeled throughout.

In a second group of cases, with injection sites in the lateral convexity (case 13B), the lateral orbitofrontal cortex (cases 5A and $8 \mathrm{~A}$ ), and in the anterior arcuate cortex (case 3A), the labeled corticostriatal projections were also predominantly distributed within the matrix, but they differed from the first group by having definitely patchy distributions within the matrix. An example of such a heterogeneous matrix-input system is shown in Figure 8. The distribution of the labeled input patches in some of these cases seemed to be nonrandom: many lay adjacent to striosomes, and some interdigitated with striosomes within the field of innervation.

In a third group of three cases, the corticostriatal labeling was not selective to either the matrix or the striosome compartment. In two of the cases (6B and 7B), the injection sites partly overlapped the caudal orbitofrontal cortex identified as having projections to striosomes and partly included more rostral orbitofrontal cortex which, in other cases, was shown to innervate primarily matrix (Fig. 1). Thus, the lack of clear differential labeling of striosomes or matrix was to be expected. However, this explanation does not account for the results in case $1 \mathrm{~A}$, in which the injection site was in the frontal pole (Fig. 1). In this case of mixed innervation, most of the labeling was in the matrix and was distinctly patchy. When compared to striosomes in serially adjoining sections, the patches of label mostly fell in the matrix. However, in every section studied, there was, nevertheless, some association between the labeled patches and striosomes. Most frequently, the input patches were situated next to striosomes, but overlapped them partially. In other instances, a striosome was found within a much larger patch of input labeling. The rare examples in which labeled patched and striosomes were strictly adjacent were nearly all in the dorsomedial part of the caudate nucleus.

\section{Discussion}

Frontostriatal circuits interconnecting the prefrontal cortex and the caudate nucleus are thought to participate in the neural activity underlying cognitive and affect-driven behaviors, and to be disordered in corresponding neuropsychiatric disorders. The experiments we report here establish that these circuits can be divided into two major sets in the macaque monkey. One originates in highly restricted regions of the posterior orbital/anterior insular cortex and the posterior medial prefrontal/anterior cingulate cortex, which preferentially innervate part of the striosomal system of the caudate nucleus. The second, much larger set of connections arises in the dorsolateral and ventrolateral prefrontal cortex and anterior frontal and anterior orbital cortex and preferentially innervates the matrix. These prefrontal inputs often form patches in the matrix (matrisomes), some of which systematically abut striosomes. These modular patterns of prefrontal projection suggest that in the primate, several mechanisms may exist for integration of corticostriatal inputs within the prefrontostriatal system as a whole.

\section{Selective inputs to striosomes from the primate prefrontal cortex}

It is striking that the posterior orbital and posterior mediofrontal sites that project to striosomes, besides the similar compartmental affiliation of their striatal projections, share anatomical connections with core structures of the limbic system such as the amygdala, the hippocampus, the medial part of the mediodorsal thalamic nucleus, the habenula, the central gray substance, and the hypothalamus (Morecraft et al., 1992). These cortical areas are also among the regions of the macaque cortex receiving both serotonergic and dopaminergic innervation (Lewis, 1992), and are transcortically interconnected (Barbas and Pandya, 1989; Ray and Price, 1993; Carmichael and Price, 1994). According to cytoarchitectural analyses, these posterior orbital and medial regions represent the least differentiated "lim bic" cortex of the frontal lobe (Sanides, 1970; Barbas and Pandya, 1989). The posterior orbital cortex, in fact, receives direct connections from olfactory cortex (Takagi, 1986; Barbas, 1993). These characteristics suggest that the major functional specializations of the striosome-projecting prefrontal cortex are tightly linked to those of the subcortical limbic system; these range from control of visceral responses and of emotions, such as the fear response for the amygdaloid complex, to the memory-related functions posited for the hippocampal formation (see, e.g., Davis, 1992; Zola-Morgan and Squire, 1993).

In humans, the orbitofrontal and the medial prefrontal-anterior cingulate areas have been implicated in behavioral and emotional responsivity and initiative (Fuster 1989; Cummings, 1993; see, e.g., Pardo et al., 1993). Moreover, the orbitofrontal and anterior cingulate cortex are the two cortical areas that, along with the head of the caudate nucleus, show differential blood flow patterns in patients suffering from obsessive-compulsive disorder (Baxter et al., 1988; Swedo et al., 1989; Insel, 1992; Rauch et al., 1994). Insofar as comparisons can be made between cortical regions in human and macaque, the neurologic and neuropsychiatric findings suggest that there may be true functional specialization of striosome-projecting prefrontal cor- 

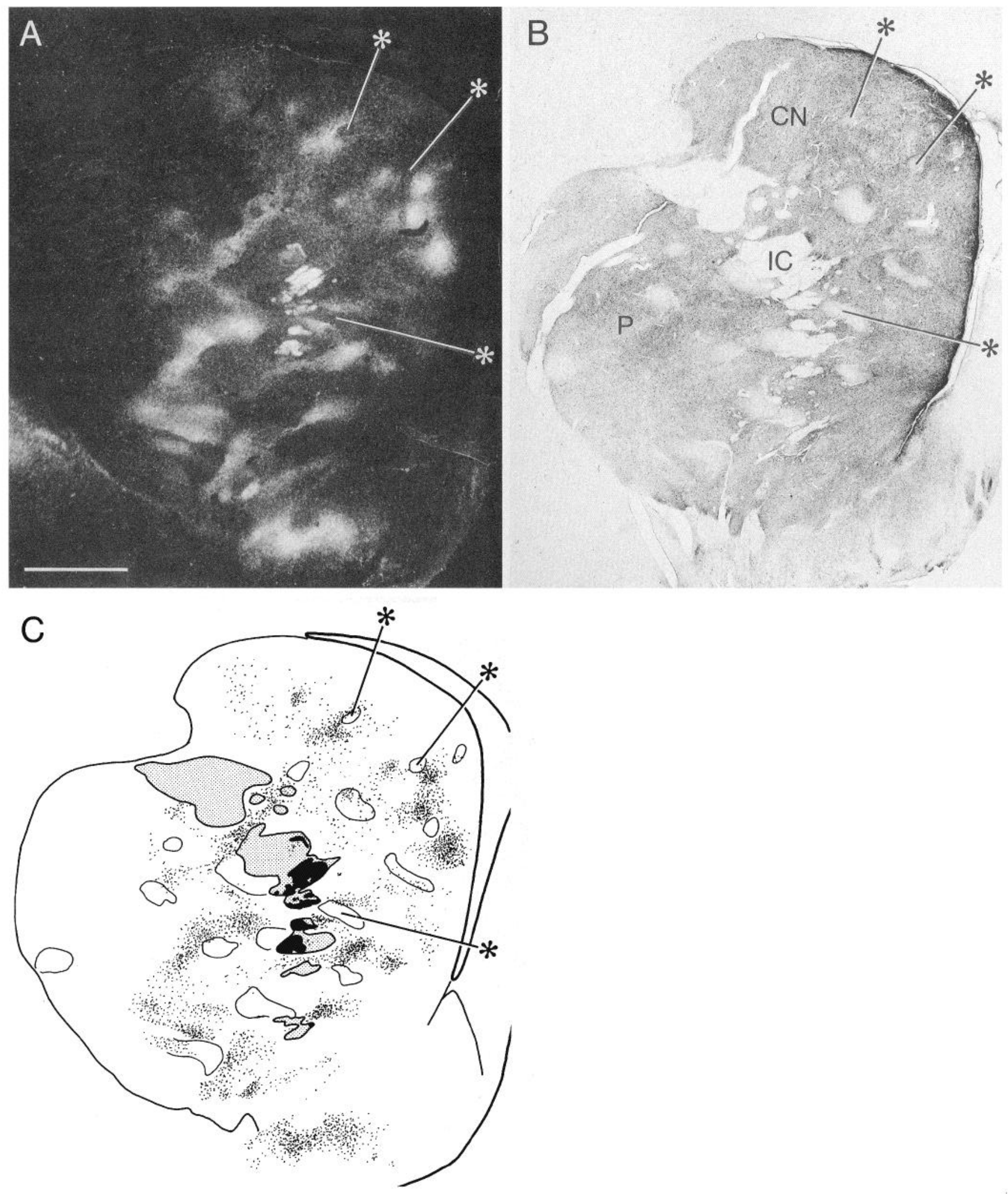

Figure 8. Some prefrontal inputs to the matrix form patches in the matrix (matrisomes) that are close to striosomes. A, Dark-field micrograph illustrating patchy autoradiographic labeling in the caudate nucleus and putamen in case $5 \mathrm{~A}$, in which the injection site was in the anterior lateral orbital cortex. $B$, Adjacent section stained for enkephalin-like immunoreactivity. $C$, Composite overlay charting of sections shown in $A$ and $B$. Striosomes are shown by fine outlines (examples at asterisks), the heavily labeled inputs by dots. The internal capsule is shown in stipple (IC), with jet black showing regions of intense capsular labeling. Note that the patches of labeling are in the matrix, and that most lie adjacent to a striosome. $\mathrm{CN}$-caudate nucleus, $P$-putamen. Scale bar in $A$ indicates $2 \mathrm{~mm}$. 

Posterior orbitofrontal-
anterior insular cortex
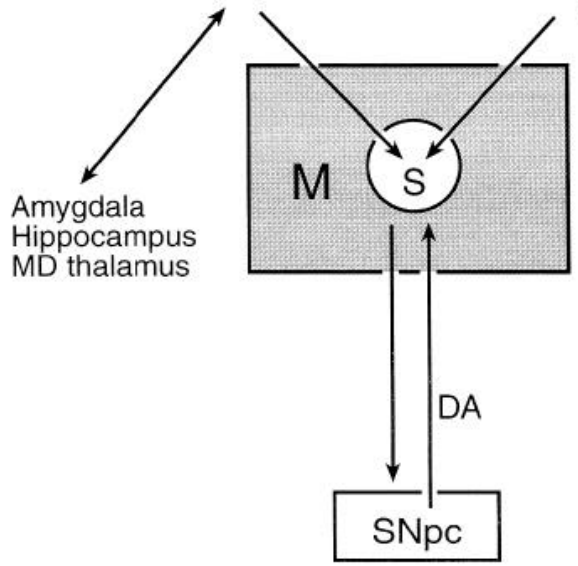

Posterior medial prefrontalanterior cingulate cortex

MD thalamus

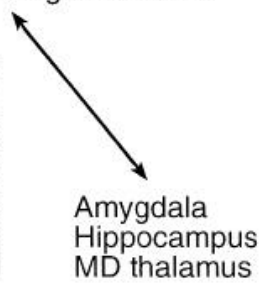

MD thalamus

Figure 9. Prefrontal subsystems targeting striosomes in the macaque monkey caudate nucleus have reciprocal connections with structures of the limbic system, and striosomes target the substantia nigra, pars compacta. Diagram summarizes main prefrontal inputs to anterior striosomal compartment $(S)$ identified in the experiments described. $M D$-mediodorsal nucleus (of thalamus); $M$-matrix compartment of striatum; $S N p c$ - pars compacta of substantia nigra; $D A$-dopamine.

tex for aspects of behavior ultimately related to behavioral drive. However, at least 22 cortical areas have been distinguished within the medial and prefrontal orbital cortex of the macaque (Carmichael and Price, 1994), and the human prefrontal cortex has been finely subdivided as well. We have identified only broad regional origins of the striosome-selective prefrontal inputs in the present study.

In such functional terms, it is particularly interesting that striosomes, unlike the matrix, are thought to send direct projections to the dopamine-containing neurons of the substantia nigra pars compacta or to their immediate vicinity (Graybiel 1990; Gerfen, 1992). Many of these dopamine-containing neurons become activated in relation to rewards and to stimuli representing rewards in behaving macaque monkeys (Schultz, et al., 1993). The present results suggest that the dopamine-containing nigral system receives a highly selective prefrontostriatal input, conveyed through striosomes, and that this input could be part of the neural mechanism related to underlying selective behavioral drive. In humans, orbitofrontal and anterior cingulate/medial prefrontal cortical areas have been suggested to collaborate in the production of neuropsychiatric symptoms found in obsessive-compulsive disorder (Baxter et al., 1988, 1992; Swedo et al., 1989; Machlin et al., 1991; Insel, 1992; Rauch et al., 1994; Schwartz et al., 1995). Our results suggest the speculation that iterative interactions between these cortical regions and the dopaminecontaining nigral neurons, conveyed via the striosomal system, might function in producing or maintaining such perseverative behavioral states (see also Damasio et al., 1990).

Although the medial prefrontal and orbitofrontal cortices were the only prefrontal sites we found to have preferential projections to striosomes, they did not innervate all of them. If the other striosomes do receive cortical inputs, they could come from the stretches of prefrontal cortex we did not inject, for example, the posterior medial orbital cortex between the medial prelimbic and the posterior orbital sites, or the dorsoanterior medial prefrontal cortex. We did see labeling of striosomes (usually with adjoining matrix) with a large polar cortical injection, but we were unable to pinpoint the origin of the striosomal input.

An interesting possibility is that other, nonfrontal areas of neocortex may project to striosomes in the monkey.

We were unable to detect dense prefrontal inputs to the nucleus accumbens, or at least to its medial part. This negative finding separates the type of "limbic" input in the prefrontostriatal system from "limbic" input carried by the direct hippocampal-accumbens pathway (Kelley and Domesick, 1982; Russchen et al., 1985). We did note, however, pronounced labeling just dorsal to the nucleus accumbens in the posterior orbitofrontal and prelimbic cases. This ventromedial labeling in the caudate nucleus and putamen appeared to be in the matrix, insofar as the compartments could be recognized. Thus, a transition zone or "prelimbic striatum" between the dorsal caudate-putamen and the nucleus accumbens could be identified on the basis of its prefrontal inputs from the cortical areas that, farther dorsally, project selectively to striosomes. This projection system resembles that showing dense autoradiographic labeling for serotonin uptake sites (Insel et al., 1992) and 5-HT receptor sites (Waeber and Palacios, 1994).

\section{Systems of prefrontal inputs to the matrix compartment of the primate striatum}

Our findings demonstrate that in the macaque monkey, as in the rat (Donoghue and Herkenham, 1986) and the cat (Ragsdale and Graybiel, 1981, 1990), much of the prefrontal cortex projects to the matrix compartment. What is striking in the monkey, with its large prefrontal cortex, is how extensive this predominantly matrix-projecting territory is. Dorsolateral, ventrolateral, anterior medial, and even lateral and anterior orbital cortex primarily target the matrix, as do the more posterior premotor areas so far investigated (Parthasarathy et al., 1992). Even the striosomeprojecting posterior orbitofrontal and prelimbic cortical areas project to ventral matrix-like tissue, as noted above.

The distributions of these matrix input systems were notable in a second respect. All of the relatively small injection sites labeled relatively discrete, patchy zones in the matrix representing the matrisomes identified in earlier experiments on inputs to the striatum from sensorimotor cortex (Flaherty and Graybiel, 1991, 1994). Only with large tracer deposits in the dorsolateral prefrontal cortex and the anterior principal sulcus was labeling distributed more broadly. We were unable to determine whether this more widespread matrix labeling resulted from the high background labeling, or to true terminal labeling. However, patchy labeling in the caudate nucleus has been observed in previous studies following dorsolateral prefrontal tracer injections (Ragsdale and Graybiel, 1981; Selemon and GoldmanRakic, 1985).

\section{Mosaic arrangement of striosomes and matrisomes innervated by different prefrontostriatal areas}

The fact that some prefrontal input matrisomes were consistently found in close spatial relationship to striosomes is of particular interest, for it suggests that although the posterior orbitofrontal and posterior medial prefrontal inputs to striosomes are spatially separated from the other prefrontal input systems, interactions among these systems might, nevertheless, occur across striosomal borders. This could be important functionally, for at least some striatal neurons at striosome-matrix borders undergo reward-related plastic changes during behavioral conditioning in the macaque (Aosaki et al., 1994, 1995; Graybiel et al., 1994). Striosome/matrisome pairs were common in cases with injections in the anterior and lateral orbital cortex. Thus, cross-com- 
partment interactions could conditionally integrate functions of anterior and posterior orbital prefrontal systems, among others. In humans, anterior and posterior orbitofrontal areas have been shown to be differently active during symptomatic episodes in obsessive-compulsive disorder (Rauch et al., 1994).

Finally, we found evidence in a few cases that some of the striosome- adjacent input patterns may even be associated with neurochemical specializations of the matrix. It has been noted repeatedly that in cats (Graybiel and Ragsdale, 1978; Graybiel ct al., 1981; Graybiel and Chesselet, 1984), monkeys (Graybiel and Ragsdale, 1978; Martin et al., 1991), and humans (Graybiel and Ragsdale, 1978; Nastuk and Graybiel, 1985; Manley et al., 1994), the ventral part of the caudate nucleus (and, in the primate, the ventral putamen) is neurochemically complex; that there are several kinds of "patches" in addition to AChE-poor striosomes; and that some neurochemical distributions switch from a pattern of patches dorsally to holes ventrally. We found clear instances in which prelimbic fibers appeared to have a dorsal-fill but ventromedial-avoid pattern (cf. Ragsdalc and Graybiel, 1990), and some of the ventrally situated fiber patches sat in enkephalin-rich zones adjacent to enkephalin-poor striosomes. Although our evidence is preliminary, it suggests that in some regions, at least, neurochemical correlates may be found for some matrisomes (cf. Aosaki et al., 1995).

\section{Associative neural processing in the caudate nucleus}

A major conceptual issue in the analysis of forebrain organization in primates is how information from the large and highly differentiated neocortex is conveyed to the much smaller subcortical targets of these inputs. Our evidence suggests that the prefrontal cortex can divide up its corticostriatal inputs into subsystems, many of which are patchy, so that different sets of input patches can overlap, abut, or be distributed with interspaces between them. This diversity of input-arrangements could provide the basis for highly effective redistribution within an associative network allowing novel combinations or dissociations of inputs so that different input-output linkages could be selected. This suggestion extends arguments made previously in relation to sensorimotor processing in the striatum (Malach and Graybiel, 1985; Flaherty and Graybiel, 1991, 1994; Brown, 1992; Parthasarathy et al., 1992; Graybiel et al., 1994). In the sensorimotor striatum, such novel associations could assist in the selection of context-dependent motor sequences and implementation strategies. Our evidence for similar heterogeneity of prefrontal cortical inputs to the matrix suggests that compartmentalization in the striatum may also permit selective interactions among cortical systems thought to carry out different cognitive tasks. Perhaps such activity in striatal networks of the caudatc nucleus could be a source of the "cognitive functions" imputed to the striatum.

\section{References}

Alexander GE, DeLong MR, Strick PL (1986) Parallel organization of functionally segregated circuits linking basal ganglia and cortex. In: Annual review of neuroscience (Cowan WM, Shooter EM, Stevens CF, Thompson RF, eds), pp 357-381. Palo Alto: Annual Reviews.

Andreasen NC, Rezai K, Alliger R, Swayze VW II, Flaum M, Kirchner P, Cohen G, O'Leary DS (1992) Hypofrontality in neuroleptic-naive patients and in patients with chronic schizophrenia. Assessment with Xenon 133 single-photon emission computed tomography and the Tower of London. Arch Gen Psychiatry 49:943-958.

Aosaki T, Tsubokawa H, Watanabe K Graybiel AM, Kimura M (1994) Responses of tonically active neurons in the primate's striatum un- dergo systematic changes during behavioral sensorimotor condition ing. J Neurosci 14:3969-3984.

Aosaki T, Kimura M, Graybiel AM (1995) Temporal and spatial characteristics of tonically active neurons of the primate's striatum. J Neurophysiol 73:1234-1252.

Barbas H (1993) Organization of cortical afferent input to orbitofrontal areas in the rhesus monkey. Neuroscience 56:841-864.

Barbas H, Pandya DN (1989) Architecture and intrinsic connections of the prefrontal cortex in the rhesus monkey. J Comp Neurol 286 : $353-375$

Baxter LR, Schwartz JM, Mazziotta JC, Phelps ME, Pahl JJ, Guze BH Fairbanks L (1988) Cerebral glucose metabolic rates in non de pressed patients with obsessive-compulsive disorder. Am J Psychiatry $145: 1560-1563$

Baxter LR Jr, Schwartz JM, Guze BH, Bergman K, Szuba MP (1990) PET imaging in obsessive compulsive disorder with and without depression. J Clin Psychiatry Suppl 51:61-69.

Baxter I.R Jr, Schwartz JM, Bergman KS, Szuba MP, Guze BH, Mazziotta JC, Alazraki A, Selin CE, Freng H-K, Phelps ME (1992) Caudate glucose metabolic rate changes with both drug and behavioral therapy in obsessive-compulsive disorder. Arch Gen Psychiatry 49: 681-689.

Benkclfat C, Nordahl TE, Scmple WE, King AC, Murphy DL, Cohen RM (1990) Local cerebral glucose metabolism rates in obsessivecompulsive disorder: patients treated with clomipramine. Arch Gen Psychiatry 47:840-848.

Berman KF, Weinberger DR (1990) The prefrontal cortex in schizophrenia and other neuropsychiatric diseases: in vivo physiological correlates of cognitive deficits. Prog Brain Res 85:521-537.

Brown LL (1992) Somatotopic organization in rat striatum: evidence for a combinatorial map. Proc Natl Acad Sci USA 89:7403-7407.

Carmichael ST, Price JL (1994) Architectonic subdivisions of the orbital and medial prefrontal cortex in the macaque monkey. J Comp Neurol 346:360-402.

Cummings JL (1993) Frontal-subcortical circuits and human behavior. Arch Neurol 50:873-880.

Damasio AR, Tranel D, Damasio H (1990) Individuals with sociopathic behavior caused by frontal damage fail to respond autonomically to social stimuli. Behav Brain Res 41:81-94.

Davis M (1992) The role of the amygdala in fear and anxiety. Annu Rev Neurosci 15:353-375.

Divac I (1972) Neostriatum and functions of prefrontal cortex. Acta Neurobiol Exp (Warsz) 32:461-477.

Donoghue JP, Herkenham M (1986) Neostriatal projections from individual cortical fields conform to histochemically distinct striatal compartments in the rat. Brain Res 365:397-403.

Drevets WC, Videen TO, Price JL, Preskorn SH, Carmichael ST, Raichle ME (1992) A functional anatomical study of unipolar depression. J Neurosci 12:3628-364l.

Eblen F, Graybiel AM (1992) Striosome/matrix affiliations of prefronto-striatal projections in the monkey. Soc Neurosci Abstr 18:309.

Eblen F, Graybiel AM (1993) Highly restricted inputs to striosomes from prefrontal cortex in the macaque monkey. Soc Neurosci Abstr $19: 576$.

Flaherty AW, Graybiel AM (1991) Corticostriatal transformations in the primate sensorimotor system. Projections from physiologically mapped body-part representations. J Neurophysiol 66:1249-1263.

Flaherty, AW, Graybiel, AM (1994) Input-output organization of the sensorimotor striatum in the squirrel monkey. J Neurosci 14:599-610.

Frith CD, Friston K, Liddle PF, Frackowiak RSJ (1991) Willed action and the prefrontal cortex in man: a study with PFT. Proc. R Soc I and [Biol] 244:241-246.

Funahashi S, Chafee MV, Goldman-Rakic PS (1993) Prefrontal neuronal activity in rhesus monkeys performing a delayed anti-saccadc task. Nature 365:753-756

Fuster JM (1989) The prefrontal cortex. New York: Raven.

Geneser-Jensen FA, Blackstad JW (1971) Distribution of acetylcholinesterase in the hippocampal region of the guinea pig. $\mathrm{Z}$ Zellforsch Mikrosk Anat 114:460-481.

Gerfen CR (1992) The neostriatal mosaic: multiple levels of compartmental organization. Trends Neurosci 15:133-139.

George MS, Ketter TA, Gill DS, Haxby JV, Ungerleider LG, Herscovitch P, Post RM (1993) Brain regions involved in recognizing facial emotion or identity: an Oxygen-15 PET study. J Neuropsychiatr Clin Neurosci 5:384-394. 
Goldman PS, Nauta WJH (1977) An intricately patterned prefrontocaudate projection in the rhesus monkey. J Comp Neurol 171:369386.

Graybiel AM (1984) Neurochemically specified subsystems in the basal ganglia. In: Ciba Foundation symposium 107, Functions of the basal ganglia (Evered D, O'Connor M, eds), pp 114-143. London: Pitman.

Graybiel AM (1990) Neurotransmitters and neuromodulators in the basal ganglia. Trends Neurosci 13:244-254.

Graybiel AM, Chesselet M-F (1984) Compartmental distribution of striatal cell bodies expressing met-enkephalin-like immunoreactivity. Proc Natl Acad Sci USA 81:7980-7984.

Graybiel AM, Ragsdale CW (1978) Histochemically distinct compartments in the striatum of human, monkey, and cat demonstrated by acetylthiocholinesterase staining. Proc Natl Acad Sci USA 75:5723 5726.

Graybiel AM, Ragsdale CW, Yoneoka ES, Elde RP (1981) An immunohistochemical study of enkephalin and other neuropeptides in the striatum of the cat with evidence that the opiate peptides are arranged to form mosaic patterns in register with striosomal compartments visible by acetylcholinesterase staining. Neuroscience 6:377-397.

Graybiel AM, Aosaki T, Flaherty AW, Kimura M (1994) The basal ganglia and adaptive motor control. Science 265:1826-1831.

Hoover JE, Strick PL (1993) Multiple output channels in the basal ganglia. Science 259:819-821.

Illing RB, Wässle H (1979) Visualization of the HRP reaction product using the polarization microscope. Neurosci Lett 13:7-11.

Insel TR (1992) Toward a neuroanatomy of obsessive-compulsive disorder. Arch Gen Psychiatry 49:739-744.

Iversen SD (1979) Behavior after neostriatal lesions in animals. In: The neostriatum (Divac I, Öberg RGE, eds), pp 195-210. Oxford: Pergamon.

Iversen SD, Mishkin M (1970) Perseverative interference in monkeys following selective lesions of the inferior prefrontal convexity. Exp Brain Res 11:376-386.

Kcllcy AE, Domesick VB (1982) The distribution of the projection from the hippocampal formation to the nucleus accumbens in the rat: an anterograde- and retrograde-horseradish peroxidase study. Neuroscience $7: 2321-2335$.

Künzle H (1975) Bilateral projections from precentral motor cortex to the putamen and other parts of the basal ganglia. An autoradiographic study in Macaca fascicularis. Brain Res 88:195-209.

Lewis DA (1992) The catecholaminergic innervation of primate prefrontal cortex. J Neural Transm Suppl 36:179-200.

Machlin SR, Harris GJ, Pearlson GD, Hoehn-Saric R, Jeffery P, Camargo EE (1991) Elevated medial-frontal cerebral blood flow in obsessive-compulsive patients: a SPECT study. An J Psychiatry 148: $1240-1242$

MacLean PD, Newman JD (1988) Role of midline frontolimbic cortex in production of the isolation call in squirrel monkeys. Brain Res 450:111-123.

Malach R, Graybiel AM (1986) Mosaic architecture of the somatic sensory-recipient sector of the cat's striatum. J Neurosci 6:34363458.

Manley MS, Young SJ, Groves PM (1991) Compartmental organization of the peptide network in the human caudate nucleus. J Chem Neuroanat 7:191-201.

Martin LJ, Hadfield MG, Dellovade TL, Price DL (1991) The striatal mosaic in primates: patterns of neuropeptide immunoreactivity differentiate the ventral striatum from the dorsal striatum. Neuroscience 43:397-417.

Mayberg HS, Starkstein SE, Sadzot B, Preziosi T, Andrezejewski PL, Dannals RF, Wagner HN Jr, Robinson RG (1990) Selective hypometabolism in the inferior frontal lobe in depressed patients with Parkinson's disease. Ann Neurol 28:57-64.

Mayberg HS, Starkstein SE, Peyser CE, Brandt J, Dannals RF, Folstein SE (1992) Paralimbic frontal lobe hypometabolism in depression associated with Huntington's disease. Neurology 42:1791-1797.

Mesulam M-M (1978) Tetramethyl benzidine for horseradish peroxidase neurohistochemistry: a non-carcinogenic blue reaction product with superior sensitivity for visualizing neural afferents and efferents. J Histochem Cytochem 26:106-117.

Mesulam M-M, Mufson EJ (1982) Insula of the old world monkey.
III: Efferent cortical output and comments on function. J Comp Neurol 212:38-52.

Morecraft RJ, Geula C, Mesulam M-M (1992) Cytoarchitecture and neural afferents of orbitofrontal cortex in the brain of the monkey. $J$ Comp Neurol 323:341-358.

Nastuk MA, Graybiel AM (1985) Patterns of muscarinic cholinergic binding in the striatuma and their relation to dopannine islands and striosomes. J Comp Neurol 237:176-194.

Pardo JV, Pardo PJ, Janer KW, Raichle, ME (1990) The anterior cingulate cortex mediates processing selection in the Stroop attentional conflict paradigm. Proc Natl Acad Sci USA 87:256-259.

Pardo JV, Fox PT, Raichle ME (1991) Localization of a human system for sustained attention by positron emission tomography. Nature 349 : $61-64$.

Pardo JV, Pardo PJ, Raichle ME (1993) Neural correlates of self in duced dysphoria. Am J Psychiatry 150:713-719.

Parent A (1990) Extrinsic connections of the basal ganglia. Trends Neurosci 13:254-258.

Park S, Holzman PS (1992) Schizophrenics show spatial working memory deficits. Arch Gen Psychiatry 49:975-982.

Parthasarathy HB, Schall JD, Graybiel AM (1992) Distributed but convergent ordering of striatal projections: the frontal eye field and the supplementary eye field in the monkey. I Nelurosci 12:4468-4488.

Paus T, Petrides M, Evans AC, Meyer E (1993) Role of human anterior cingulate cortex in control of oculomotor, manual, and speech responses: a positron emission tomography study. J Ncurophysiol 70 : 453-469.

Petrides M, Alivisatos B, Meyer E, Evans AC (1993) Functional activation of the human frontal cortex during the performance of verbal working memory tasks. Proc Natl Acad Sci USA 90:878-882.

Posner MI, Petersen SE, Fox PT, Raichle ME (1988) Localization of cognitive operations in the human brain. Science 240:1627-1631.

Ragsdale CW, Graybiel AM (1981) The fronto-striatal projection in the cat and monkey and its relationship to inhomogeneities established by acetylcholinesterase histochemistry. Brain Res 208:259-266.

Ragsdale CW, Graybiel AM (1990) A simple ordering of neocortical areas established by the compartmental organization of their striatal projections. Proc Natl Acad Sci USA 87:6196-6199.

Rauch SL, Jenike MA, Alpert NM, Baer L, Breiter HC, Savage CR, rischman AJ (1994) Regional cerebral blood flow measured during symptom provocation in obsessive-compulsive disorder using oxygen 15-labeled carbon dioxide and positron emission tomography. Arch Gen Psychiatry 51:62-70.

Ray JP, Price JL (1993) The organization of projections from the mediodorsal nucleus of the thalamus to orbital and medial prefrontal cortex in macaque monkeys. J Comp Neurol 337:1-31.

Rosenkilde CE, Bauer RH, Fuster JM (1981) Single cell activity in ventral prefruntal cortex of behaving monkeys. Brain Res 209:375394.

Rosvold HE (1972) The frontal lobe system: cortical-subcortical interrelationships. Acta Neurobiol Exp 32:439-460.

Rubin RT, Villanueva-Meyer J, Ananth J, Trajmar PG, Mena I (1992) Regional xenon 133 cerebral blood flow and cerebral technetium $99 \mathrm{~m}$ HMPAO uptake in unmedicated patients with obsessive-compulsive disorder and matched normal control subjects. Arch Gen Psychiatry 19:695 702.

Russchen FT, Bakst I, Amaral DG, Price JL (1985) The amygdalostriatal projections in the monkey. An anterograde tracing study. Brain Res 329:241-257.

Sanides F (1970) Functional architecture of motor and sensory cortices in primates in light of a new concept of neocortex evolution. In: The primate brain (Noback CR, Montagna W, eds), pp 137-208. New York: Appleton-Century-Crofts.

Sawaguchi T, Goldman-Rakic PS (1991) D1 dopamine receptors in prefrontal cortex: involvement in working memory. Science 251:947950 .

Sawle GV, Hymas NF, Lecs AJ, Frackowiack RSJ (1991) Obscssional slowness. Functional studies with positron emission tomography. Brain 1 14:2191-2202.

Schultz W, Apicella P, Ljungberg 'T' (1993) Responses of dopamine neurons to reward and conditioned stimuli during successive steps of learning a delayed response task. J Neurosci 13:900-913.

Schwartz JM, Stoessel PW, Baxter LR Jr, Martin KM, Phelps ME (1995) Systemic cerebral glucose metabolic rate changes after suc- 
cessful behavior modification treatment of obsessive-compulsive disorder. JAMA, in press.

Selemon LD, Goldman-Rakic PS (1985) Longitudinal topography and interdigitation of corticostriatal projections in the rhesus monkey. $\mathbf{J}$ Neurosci 5:776-794.

Swedo SE, Schapiro MB, Grady CL, Cheslow DL, Leonard HL, Kumar A, Friedland R, Rapoport SI, Rapoport JL (1989) Cerebral glucose metabolism in childhood-onset obsessive-compulsive disorder. Arch Gen Psychiatry 46:518-523.

Swedo SE, Pietrini P, Leonard HL, Schapiro MB, Rettew DC, Goldberger EL, Rapoport SI, Rapoport JL, Grady CL (1992) Cerebral glucose metabolism in childhood-onset obsessive-compulsive disorder. Revisualization during pharmacotherapy. Arch Gen Psychiatry 49:690-694.

Takagi, SF (1986) Studies on the olfactory nervous system of the old world monkey. Prog Neurobiol 27:195-250.

Tehovnik EJ, Lee K-M (1990) Electrical stimulation of the dorsomedial trontal cortex (DMFC) of the rhesus monkey. Soc Neurosci Abstr $16: 900$.
Teuber H-L, Proctor F (1964) Some effects of basal ganglia lesions in subhuman primates and man. Neuropsychology 2:85-93.

Waeber C, Palacios JM (1994) Binding sites for 5-hydroxytryptamine-2 receptor agonists are predominantly located in striosomes in the human basal ganglia. Mol Brain Res 24:199-209.

Walker AE (1940) A cytoarchitectural study of the prefrontal area of the macaque monkey. J Comp Neurol 73:59-86.

Webster KE (1965) The cortico-striatal projection in the cat. J Anat 99:329-337.

Yamamoto T, Oomura $\mathrm{Y}$, Nishino $\mathrm{H}$, Aou S, Nakano $\mathrm{Y}$, Nemoto $\mathrm{S}$ (1984) Monkey orbitofrontal neuron activity during emotional and feeding behaviors. Brain Res Bull 12:441-443.

Yeterian EH, Pandya DN (1991) Prefrontostriatal connections in relation to cortical architectonic organization in rhesus monkeys. J Comp Neurol 312:43-67.

Yeterian EH, Van Hoesen GW (1978) Cortico-striate projections in the rhesus monkey: the organization of certain cortico-caudate connections. Brain Res 139:43-63.

Zola-Morgan S, Squire LR (1993) Neuroanatomy of memory. Annu Rev Neurosci 16:546-563. 